\title{
HEPATITIS ASSOCIATED WITH INFANTILE DIARRHOEA
}

BY

\author{
J. WAINWRIGHT \\ From the Department of Pathology, Victoria University of Manchester
}

(Received for Pubucation October 26, 1949)

Clinically, enlargement of the liver, jaundice and haemorrhages are well known complications occurring with infantile diarrhoea. But the pathological changes in the liver are not well defined. In a recent paper (Schlesinger, Payne, and Burnard, 1949) state that the histological changes have not been constant and do not fall into any well-defined groups. They found fatty infiltration, dilatation of the sinusoids, parenchymal degeneration, cellular necrosis, and cell infiltration with early fibrosis in some cases. Others have described changes varying from moderate periportal fatty degeneration to generalized fatty change with cellular necrosis (Blacklock, Guthrie, and Macpherson, 1937; Bray, 1945; Christensen and Biering-Soerensen, 1946; Giles, 1948). In addition to fatty change, Sakula (1943) noted in some cases an 'early proliferation of

bile canaliculi as seen in adult cirrhosis' and that 'these changes were most conspicuous in the jaundiced livers'.

Most cases of infantile diarrhoea show no pathological evidence of gastro-enteritis, and one is uncertain not only of the basic pathology of the condition, but even whether one is dealing with a single entity or a group of conditions. The number of cases showing acute ulcerative enteritis is small, but the following 15 cases have been collected from 350 consecutive necropsies at the Duchess of York Hospital for Babies, Manchester, and have been divided into two groups, those with jaundice and those without (Table 1). Thus five of 15 cases with an acute ulcerative enteritis show a form of hepatitis, and this is more common in the jaundiced cases in which the most severe liver damage might be

TABLE 1

Incidence of Hepatimis in Cases of Acute Ulcerative Enteritis

Pathological Changes in the Liver

\begin{tabular}{|c|c|c|c|c|c|c|c|}
\hline & \multirow[b]{2}{*}{$\begin{array}{c}\text { No. of } \\
\text { Cases }\end{array}$} & \multirow[b]{2}{*}{ 'Hepatitis' } & \multirow[b]{2}{*}{$\begin{array}{l}\text { Capillary } \\
\text { Biliary } \\
\text { Thrombi }\end{array}$} & \multirow[b]{2}{*}{$\begin{array}{c}\text { Fatty } \\
\text { Infiltration }\end{array}$} & \multirow[b]{2}{*}{ Atrophy } & \multirow[b]{2}{*}{$\begin{array}{l}\text { Foci of } \\
\text { Erythro- } \\
\text { poiesis }\end{array}$} & \multirow[b]{2}{*}{ No change } \\
\hline Group & & & & & & & \\
\hline Cases with jaundice .. & 8 & 4 & 3 & 0 & 0 & 1 & 0 \\
\hline Cases without jaundice & 7 & 1 & $\mathbf{0}$ & 2 & 1 & 0 & 3 \\
\hline
\end{tabular}

TABLE 2

InCidence of Hepatitis in all Cases of Infants Dying with Jaundice

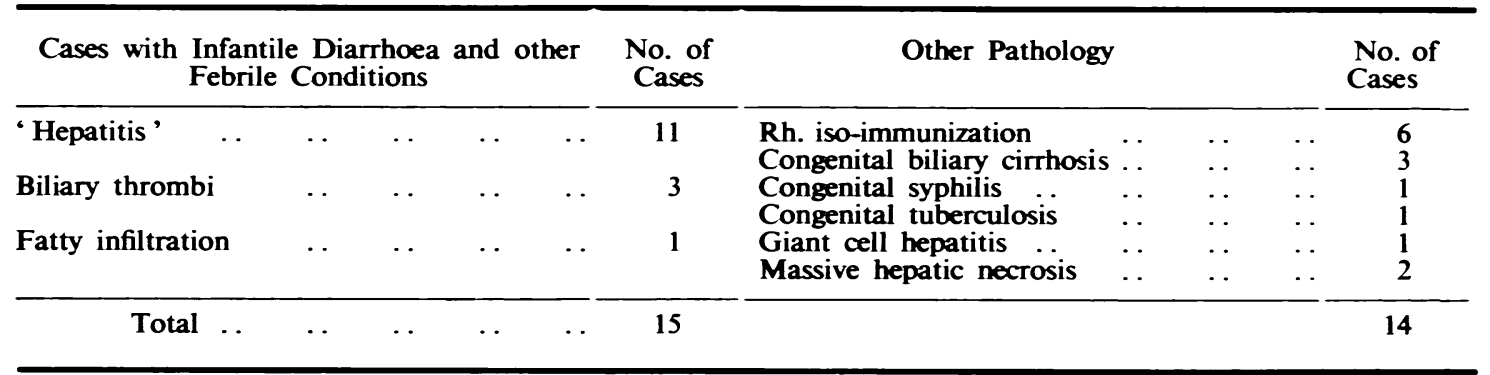


expected. If we now consider all the cases of infants dying with jaundice (excluding physiological icterus) in this series of necropsies, we find that hepatitis is the most common finding associated with jaundice in infancy.

The group of cases with infantile diarrhoea will be considered in detail (Table 2). Material from the liver, pancreas, umbilicus, and other organs was available for examination in most cases. Special attention was paid to the umbilical vessels since infection can lead to liver changes (Morison, 1944); to the pancreas, in view of the cirrhosis described in association with cystic fibrosis of the pancreas (Farber, 1944); and to the bile passages, since 'ascending infection' of the bile ducts is often considered to be the cause of jaundice. Frozen sections were stained by sudan IV for fat. Paraffin sections were stained by haemalum and eosin, Weigert's haematoxylin and van Giesen, Lillie Gram stain, and Gomori's reticulin silver impregnation technique. Most of the necropsies were on infants under one year, the average age being about two months.

Group 1 consisted of cases of acute hepatitis with bile duct proliferation. Under $A$ are studied cases with severe jaundice and marked histological changes in the liver (Table 3 ).

\section{Clinical Summaries (Group A.)}

Case 1. The infant developed diarrhoea and vomiting eight days following mastoidectomy and jaundice appeared after seven days. The jaundice deepened and he became comatose and died seven days later.

Case 2. The stools became pale and offensive six days before admission, and four days later the infant developed diarrhoee and vomiting. Bruising of the abdominal wall appeared and he died 24 hours later.

Case 3. Jaundice was first noticed two days before admission and since then there had been diarrhoea and vomiting. The infant died three days later.
Case 4. A premature infant, who developed attacks of cyanosis at two weeks, following admission to hospital, developed diarrhoea and vomiting which persisted for 11 days. He became jaundiced and emaciated.

\section{Naked Eye Appearance of the Liver}

In each case the liver was enlarged, green or greenish-yellow, and showed marked centrilobular congestion. The capsule was smooth and there was no distortion of the pattern.

\section{Histological Features}

In cases 1, 2, and 3 the liver showed a severe periportal fatty infiltration (Fig. 1) but in case 4 there was no fat present, and the cells were shrunken and the sinusoids dilated. There was necrosis of

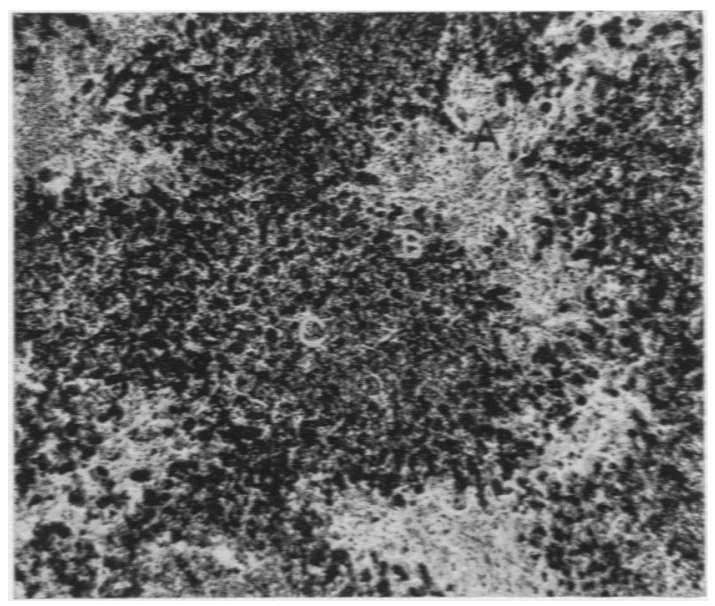

FIG. 1.-Case 1. Liver showing marked periportal fat infiltration. A, widened portal tracts. B, periportal zone. C, centre lobule. Fat appears black. Sudan IV. $\times 60$.

TABLE 3

Cases of Hepatmins with Severe Jaundice

\begin{tabular}{|c|c|c|c|c|c|c|}
\hline Case & Age & Sex & W.B.C. & $\begin{array}{c}\text { Duration } \\
\text { Jaundice } \\
\text { (Days) }\end{array}$ & Alimentary Tract & Other Pathology \\
\hline 1 & 9 months & M. & $\begin{array}{l}16,000 \\
\text { P.65\% }\end{array}$ & 7 & $\begin{array}{l}\text { Acute enteritis with } \\
\text { pneumatosis }\end{array}$ & Recent mastoidectomy. \\
\hline 2 & 6 weeks & M. & $\begin{array}{l}25,600 \\
\mathbf{P} .85^{\circ}\end{array}$ & 7 & No inflammation & $\begin{array}{l}\text { Impervious cystic duct. } \\
\text { Bronchopneumonia. }\end{array}$ \\
\hline 3 & 3 weeks & F. & $\begin{array}{l}17,600 \\
\text { P. } 70^{\circ}{ }_{\circ}^{\circ}\end{array}$ & 5 & No inflammation & $\begin{array}{l}\text { Acute pancreatitis. } \\
\text { Bronchopneumonia. }\end{array}$ \\
\hline 4 & 6 weeks & M. & & 7 & $\begin{array}{l}\text { Acute enterocolitis with } \\
\text { "pneumatosis" }\end{array}$ & $\begin{array}{l}\text { Splenomegaly with fibrinous } \\
\text { perisplenitis. }\end{array}$ \\
\hline
\end{tabular}




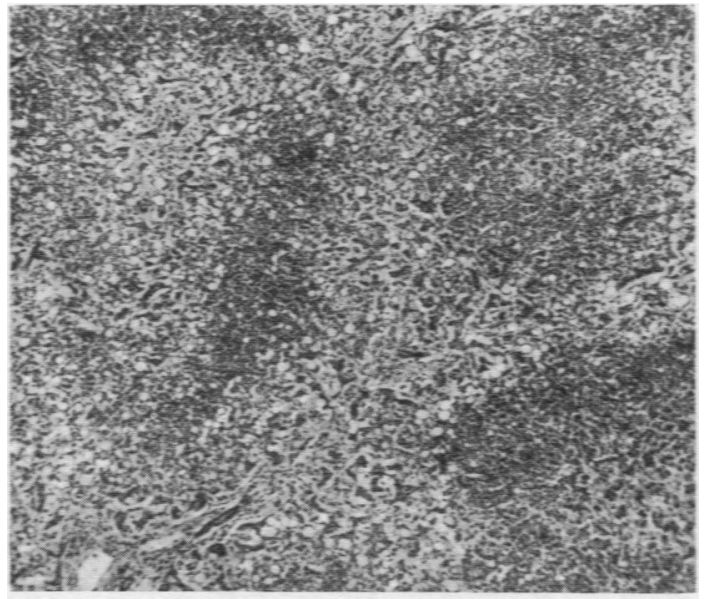

Frg. 2.-Case 1. Liver showing proliferation of bile canaliculi around the portal tracts, with centrilobular congestion. H.E. $\times 60$.

parenchymal cells in the periportal zone of the lobule with a scattered infiltration of mononuclears and polymorphs. The most striking feature was the proliferation of bile canaliculi in this zone, frequently involving half the lobule (Figs. 2 and 3 ). Mitoses were present in cells of these bile canaliculi. There was also proliferation of fibroblasts, and in case 1 sections stained by van Giesen showed an increase of pink staining fibres. There was marked centrilobular congestion with varying degrees of

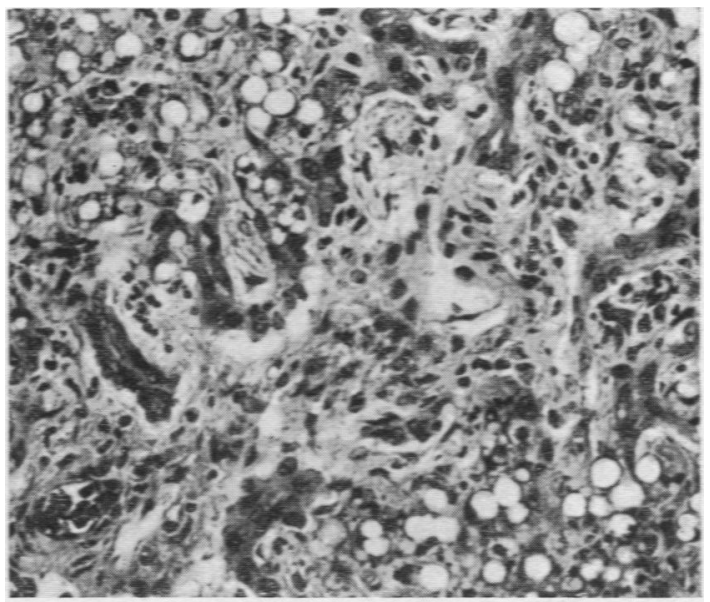

FIG. 3.-Case 2. Liver showing proliferating bile canaliculi, inflammatory cells and fatty infiltration. H.E. $\times 220$.

centrilobular necrosis. The intercellular bile capillaries at the centre of the lobules were distended with bile. No organisms could be demonstrated. Case 3 showed microscopic evidence of an acute pancreatitis but there was no evidence of infection involving the bile ducts or the umbilicus vessels in any of the cases.

Under B cases with moderate jaundice and less severe histological changes in the liver were studied (Table 4).

TABLE 4

Cases of Hepatims with Moderate Jaundice

\begin{tabular}{|c|c|c|c|c|c|c|}
\hline Case & Age & Sex & $\begin{array}{l}\text { W.B.C. } \\
\text { (c.mm.) }\end{array}$ & $\begin{array}{c}\text { Duration } \\
\text { Jaundice } \\
\text { (Days) }\end{array}$ & Alimentary Tract & Other Pathology \\
\hline 5 & 4 weeks & M. & $\begin{array}{l}30,000 \\
\text { Protein } 75 \%\end{array}$ & 2 & Ulcerative enteritis & Haemorrhages on the pleura \\
\hline 6 & 3 weeks & $\mathbf{M}$. & $\begin{array}{c}15,000 \\
\text { Protein } 68 \%\end{array}$ & 12 & No inflammation & Haemorrhages in the brain \\
\hline 7 & 3 weeks & M. & $\begin{array}{c}8,400 \\
\text { Protein } 31 \%\end{array}$ & 2 & No inflammation & - \\
\hline 8 & 10 months & F. & $\begin{array}{c}\mathbf{6 , 6 0 0} \\
\text { Protein } 26 \%\end{array}$ & 1 & No inflammation & Coeliac syndrome \\
\hline 9 & 10 weeks & F. & - & 2 & No inflammation & $\begin{array}{l}\text { Acute meningitis. Streptococcal } \\
\text { haemolytic septicaemia }\end{array}$ \\
\hline 10 & 4 weeks & $\mathbf{F}$. & $\begin{array}{c}19,600 \\
\text { Protein } 47 \%\end{array}$ & 4 & Ulcerative enteritis & Haemorrhages in the meninges \\
\hline 11 & 3 weeks & F. & - & & No inflammation & - \\
\hline
\end{tabular}


Clinical Summaries (Group B)

Case 5. The infant developed diarrhoea and vomiting following a Ramstedt operation and three days later became jaundiced. The following day he vomited blood-stained material, had severe melaena, and died.

Case 6. The infant had severe jaundice with a profuse aural discharge at ten days. The stools and urine were nor mal until seven days later when he developed diarrhoea and vomiting.

Case 7. Diarrhoea and vomiting began three days after admission, and five days later the infant became jaundiced and died the following day.

Case 8. This case presented as a coeliac syndrome and improved for three weeks, when the baby started diarrhoea and vomiting, developed slight icterus, and rapidly deteriorated.

Case 9. The illness began with convulsions and presented as meningitis. The baby was treated by chemotherapy and penicillin, but developed progressive jaundice.

Case 10. The infant had always been slow with feeds and the motions relaxed. Jaundice was noted the day before admission and she died three days later.

Case 11. The infant developed diarrhoea and vomiting and was jaundiced and moribund on admission.

Naked Eye Appearance of the Liver

In each case the liver was enlarged, bright yellow, or showing marked fatty change. The capsule was smooth and there was no distortion of the pattern.

\section{Histological Features}

The histological features were similar to those in Group A but less severe. All cases showed a periportal fat infiltration though this was very small in case 9. There was necrosis of parenchymal cells in the periportal zone with an infiltration of mononuclears and lymphocytes. Proliferating bile canaliculi and fibroblasts were present but not involving so much of the lobule. No organisms were seen and there was no indication of infection of the bile ducts. In case 6 , in which the jaundice had been prolonged, there was an increase in pink staining fibres with van Giesen stain around the portal tracts. Case 8 showed an intense fat infiltration of the whole lobule with many cells ballooned and frequently degenerating. This was associated with atrophy of the pancreatic acinar tissue.

Group 2 consisted of cases of infantile diarrhoea with jaundice not showing hepatitis.

There were three cases showing ulcerative enteritis with jaundice of one to six weeks ${ }^{\circ}$ duration, in which the liver was enlarged and dark green. The essential histological feature was distension of the intercellular bile capillaries in the absence of an inflammatory reaction, fatty infiltration or swelling of the parenchymal cells, or obstruction of the bile ducts. The fourth case was an infant with fibrinous pericarditis and mild jaundice of two days' duration. The liver showed periportal fatty infiltration but no bile duct proliferation, inflammatory infiltration, or distension of the bile capillaries. The available data are not sufficient to determine the cause of the jaundice in these cases, but the histological findings in the liver suggest a non-hepatic origin.

\section{Discussion}

Of these 15 cases of jaundice associated with infective conditions 11 fall into the same group, the essential features of which are necrosis of parenchymal cells around the portal tracts with a proliferation of bile canaliculi and fibroblasts, and an infiltration of inflammatory cells. It is an acute process and, as shown by the severe cases in Group A, half the lobule can be replaced by proliferating bile canaliculi when jaundice has lasted seven days. Most cases show a marked periportal fatty infiltration, but the severity is variable, and in case 4 no fat was present in the liver. The liver was invariably enlarged and the colour was dark green when jaundice had lasted about seven days, and a bright yellow with a shorter duration. Sakula (1943) noted the proliferation of bile canaliculi, but it is surprising that this has not been commented upon by others. Giles (1948) reported on 55 necropsies, 13 showing jaundice, but did not remark on any proliferation of bile canaliculi. But one of his illustrations showing 'periportal distribution of fatty degeneration' shows structures which clearly resemble bile canaliculi.

Liver sections from 200 infants were examined to determine whether these histological features occurred without jaundice. In cases showing appreciable periportal fat infiltration the small bile ducts may appear more prominent owing to

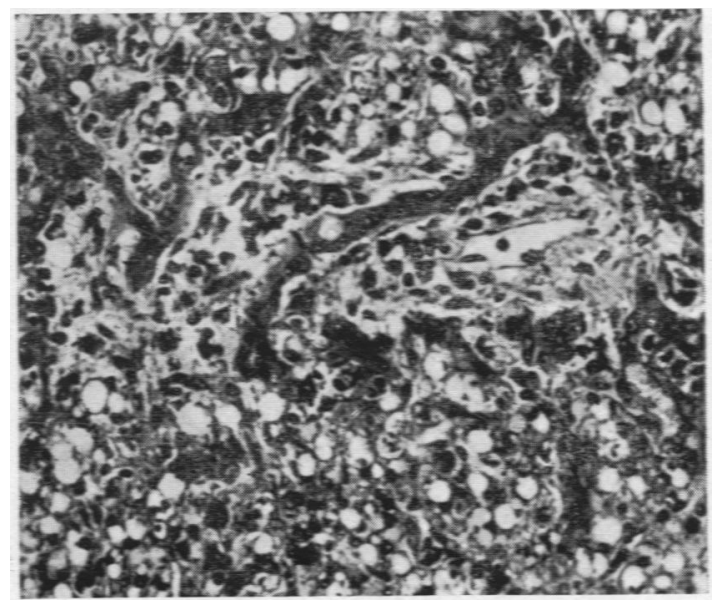

FIG. 4.-Cretin with ulcerative colitis, but no jaundice. Liver showing proliferating bile canaliculi, inflammatory cells and fatty infiltration. H.E. $\times 220$. 
vacuolation of the liver cells, but proliferation of bile canaliculi was found in only one case without jaundice (Fig. 4). This was a girl aged $4 \frac{1}{2}$ months, a cretin who developed otitis media and ulcerative enteritis (case included in Table 1). The intercellular bile capillaries were distended with bile suggesting that jaundice would have appeared had life been prolonged.

Most of the cases have a definite history of severe diarrhoea and vomiting with the development of an enlarged liver, jaundice, and occasionally haemorrhages, but in only four cases was there pathological evidence of acute entero-colitis, two of these also showing 'pneumatosis' of the bowel wall. In case 2 jaundice appeared to precede the diarrhoea and vomiting, but histories of young infants are not always reliable. In case 6 jaundice was at first associated with otitis media, while case 9 presented with meningitis and septicaemia and no history of diarrhoea. Thus, although this form of hepatitis apparently can occur with other infective conditions, it is most commonly associated with infantile diarrhoea.

Fat infiltration of the liver is the most constant change which has been described in association with infantile diarrhoea. It can be caused experimentally by various poisons such as phosphorus and chloroform, and also by dietary deficiency. Fat infiltration of the liver also occurs in fasting animals (Mottram, 1909; Dible, 1932). In the mouse, fat infiltration is marked after 24 hours ${ }^{\circ}$ starvation, but by the third and fourth days, when all available carcase lipids have been mobilized, the liver contains no

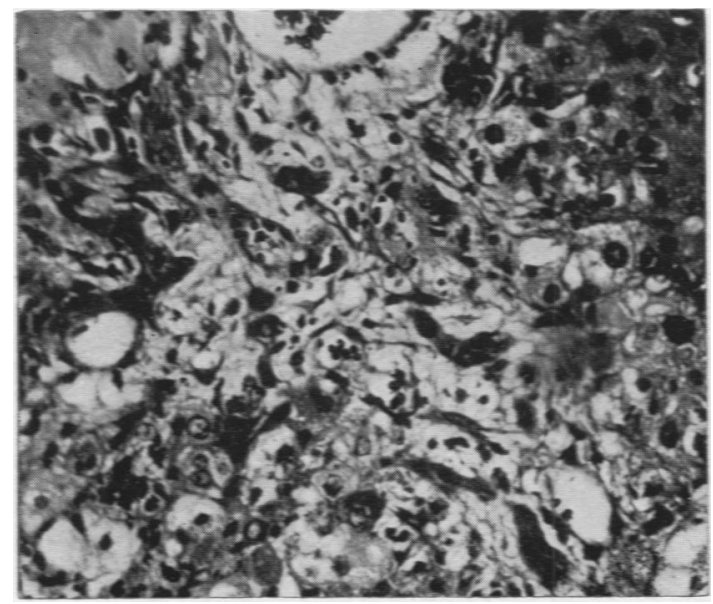

FIG. 5.-Rat liver. Allyl formate. Proliferation bile canaliculi and cell necrosis around portal tract seven days after initial dose. ( $.015 \mathrm{ml}$. alternate days, 3 doses.) H.E. $\times 220$. stainable fat (Hodge, McLachlan, Bloor, Stoneburg, Oleson, and Whitehead, 1941). Thus in the fasting mouse fatty infiltration of the liver is a physiological process and is not an indication of serious liver damage. Fat infiltration is much more common in infants than in adults, being found in about $50^{\circ}{ }_{0}$ of necropsies (65 of 135 livers in this series). It appears to be related to the nutritional state of the infant, being scanty with emaciation. This high incidence in infancy may be related to the high metabolic rate. Thus the fat infiltration associated with infantile diarrhoea may be toxic or may be a physiological reaction to starvation. It is not possible to evaluate the relative importance of these factors. The absence of fat in the liver in case 4 , where there is marked proliferation of bile canaliculi, suggests that fat infiltration and necrosis of the liver cells are not dependent processes.

It is known that necrosis of liver parenchymal cells may be caused either by deficiency of factors essential to cellular activity, or by a toxic process (Himsworth, 1947). Deficiency necrosis is commonly of massive type, although this mechanism is believed to operate in centrilobular necrosis where some toxin, as with $\mathrm{CCl}_{4}$ or infective hepatitis, causes swelling of the peripheral cells with obstruction of the intralobular circulation. Other poisons, such as allyl formate (Himsworth, 1947), especially when given by intraperitoneal injection, produce a peripheral zonal necrosis. If repeated small doses of allyl formate are given to a rat or rabbit, then proliferation of bile canaliculi occurs around the portal tracts (Figs. 5 and 6 ), comparable to that

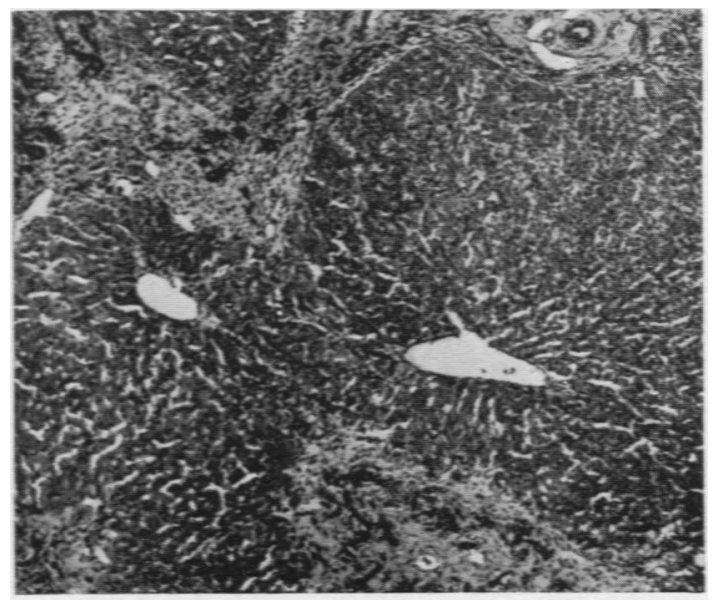

FIG. 6.-Rabbit liver. Allyl formate. Fibrosis and proliferation bile canaliculi around portal tracts with normal central veins. Thirteen days after initial dose. $(0 \cdot 1 \mathrm{ml}$. first and fifth days.) H.E. $\times 60$. 
found in these cases of hepatitis. We do not see the same extensive peripheral zonal necrosis in hepatitis in infants, but this can be explained by the slower access of toxin to the liver. Proliferation of bile canaliculi appears to follow any liver cell necrosis in which rapid regeneration of the liver cells does not occur. It seems probable that they are formed by a proliferation of cells (as evidenced by mitoses) from the bile ducts, which then grow along the intercellular bile capillaries in an endeavour to form functional continuity with the remaining viable liver cells.

The histological features of this form of hepatitis somewhat resemble subacute cholangio-hepatitis in the adult, where proliferation of bile canaliculi and fibroblasts follows an inflammatory necrosis of cells around the portal tracts (Himsworth, 1947). Cholangio-hepatitis is commonly associated with obstruction of the bile ducts and the primary lesion is cholangitis. In these infants there is no obstructive lesion and the absence of an inflammatory process involving the bile ducts and the rarity of inflammatory lesions in the duodenum is clear evidence that the process does not arise as cholangitis.

This form of hepatitis is quite distinct histologically from the interstitial hepatitis described by Morison (1944) and Lesage and Demelin (1898) in cases with umbilical infection. It also differs from the lesion in infective jaundice of intestinal origin described by Lesage and Demelin (1898), which appeared to be a massive hepatic necrosis. It is distinct from infective hepatitis, where centrilobular necrosis is the salient feature and bile duct proliferation is not found unless massive necrosis occurs (Himsworth, 1947). The regularity of the lesion and the periportal distribution distinguish it clearly from subacute hepatic necrosis which is now recognized to be the lesion in 'biliary cirrhosis' of Hindu infants (Himsworth, 1947).

Case 8 differed from the others in that the hepatic lesion was associated with atrophy of pancreatic acinar tissue, and the fat infiltration was diffuse and severe. Prolonged fatty infiltration due to dietary deficiency may lead to a diffuse hepatic fibrosis involving both the portal tracts and central veins (Himsworth, 1947). But the histology in case 8 bears no resemblance to diffuse hepatic fibrosis and is definitely an acute process localized to the periportal zone. Nor does it resemble the groups of dilated ducts containing eosinophilic material described by Farber (1944) in the liver in cystic fibrosis of the pancreas.

This form of hepatitis appears to be limited largely to infancy when it is apparently a common cause of fatal jaundice. Himsworth (1947) discusses experi- mental peripheral zonal necrosis but does not give any examples in human pathology. It is possible that the liver cells in infancy are more easily damaged than in adult life. The histological picture with periportal bile duct proliferation might be termed a "biliary cirrhosis," although in most cases there has been insufficient time for fibrosis to occur, and the problem arises as to whether there is any relation between the aetiology of this form of hepatitis and congenital biliary cirrhosis. It is generally assumed that the latter is of obstructive origin, but many cases occur in the absence of atresia of the bile ducts. As originally suggested by Rolleston and McNee (1929), some intra-uterine toxin may produce a periportal necrosis of liver cells, and the frequent occurrence of this reaction in infancy adds support to this hypothesis.

\section{Summary}

A form of hepatitis associated with jaundice and infantile diarrhoea is described. The main features are a periportal necrosis of parenchymal cells, with an infiltration of inflammatory cells, and a proliferation of bile canaliculi and fibroblasts. Most cases show fatty infiltration.

The aetiology is discussed and it is considered that the hepatitis is caused by a toxin reaching the liver by the blood stream.

A possible relationship between this form of hepatitis and congenital biliary cirrhosis is suggested.

I wish to thank the honorary staff of the Duchess of York Hospital for Babies, Manchester, for the clinical notes, Professor S. L. Baker for helpful advice, and Mr. F. Ward for the photomicrographs.

\section{REFERENCES}

Blacklock, J. W. S., Guthrie, K. J., and Macpherson, I. (1937). J. Path. Bact., 44, 321.

Bray, J. (1945). Ibid., 57, 239.

Christensen, E., and Biering-Soerensen, K. (1946). Acta path. microbiol. scand., 23, 395.

Dible, J. H. (1932). J. Path. Bact., 35, 451.

Farber, S. (1944). Arch. Path., 37, 238.

Giles, C. (1948). 'Infantile Gastro-enteritis.' M.D. thesis, Victoria University of Manchester.

Himsworth, H. P. (1947). ' The Liver and its Diseases.' Oxford.

Hodge, H. C., McLachlan, P. L., Bloor, W. R., Stoneburg. C. A., Oleson, C., and Whitehead, R. (1941). J. biol. Chem., 139, 897.

Lesage, - - ., and Demelin, -. -. (1898). Rev. Médecine, 18, 1.

Morison, J. E. (1944). J. Path. Bact., 56, 531.

Mottram, V. H. (1909). J. Phy'siol., 38, 281.

Rolleston, H., and McNee, J. W. (1929). 'Diseases of the Liver, Gall-bladder and Bile Ducts.' 3rd edit. London.

Sakula, J. (1943). Lancet, 2, 758.

Schlesinger, B., Payne, W. W., and Burnard, E. D. (1949). Arch. Dis. Childh., 24, 15. 